\title{
$\mathrm{CAD} / \mathrm{CAM}$ 전용 금속 합금과 주조용 합금의 세라믹 결합강도에 관한 연구
}

정 효 경, 곽 동 주

대구보건대학교 치기공과

\section{A Study on the Metal-Ceramic Bond Strength of CAD/CAM Metal Disk Alloy and Casting Alloy}

\author{
Hyo-Kyung Jung, Dong-Ju Kwak
}

Dept. of Dental Technology, Daegu Health College

\section{[Abstract]}

Purpose: The purpose of this study was to evaluate bond strength of Metal Disk alloy and casting alloy.

Methods: Metal specimens were divided into 4 groups for each alloy. Three point flexural test were used to measure the bond strength of CAD/CAM metal alloy and casting alloy. Statistical analysis was done using the Statistical Package for Social Sciences version 19.0 for Windows. As for the analysis methods, the study used Kruskal-Wallis test.

Results: The average bonding strengths of Group 1 to porcelain was $36.7 \pm 9.90 \mathbb{M P a}$, Group 2 to porcelain was $37.68 \pm 4.51 \mathrm{MPa}$, Group 3 to porcelain was $36.43 \pm 6.57 \mathrm{MPa}$, Group 4 to porcelain was $42.88 \pm 6.81 \mathrm{MP}$, Each group was not significantly different.

Conclusion: Bond strength of Casting alloy is equal to or higher than bond strength of CAD/CAM Metal Disk alloy. Alloy clinical bond strength is $25 \mathrm{MPa}$, So CAD/CAM Metal Disk alloy can be used as dental material.

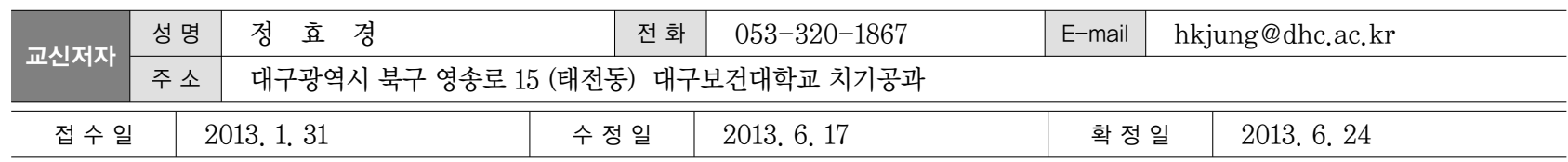




\section{I. 서 론}

심미적인 보철치료에 대한 환자들의 요구에 의해 금속 을 사용하지 않는 전부도재관의 개발과 발전에 초점이 맞 추어졌지만, 치과 현장에서는 금속-세라믹 보철이 널리 사용되고 있는 실정이다(Azer et al., 2006). 금속-세라 믹 보철은 금속의 견고성과 도재의 심미성을 함께 갖춘 우수한 수복물로, 제작에 사용되는 주조용 금속은 귀금속 과 비귀금속으로 대별된다(Bagby and Marchall, 1990; Dent, 1982). 귀금속은 주조성이 좋고 연성, 전성 및 부식 저항성이 높으며 도재 색조표현에 유리하지만 고가이고, 비귀금속은 기계적 성질은 우수하지만 생체 적합성과 부 식 저항성이 낮은 단점 등을 가지고 있다(Moffa, 1983, Moffa et al 1973; Kelly and Rose, 1983).

금속-세라믹관용 합금이 갖추어야 할 요건은 포세린과 의 강한 결합력, 포세린과 합금간의 열 팽창 계수의 조화, 포세린 소성 시 변형에 저항할 수 있는 능력 등이다 (Craig, 1997). 그 중 금속과 포세린의 결합기전은 화학적 결합, 기계적 결합, 포세린과 금속의 열팽창계수 차이에 서 오는 압축강도에 의한 결합, 판데르 바알스의 힘 등이 있으며 이러한 결합력이 복합적으로 작용하여 결합력을 높이게 된다(Bagby and Marchall, 1990).

기존의 금속-세라믹 보철은 지대치 위에 왁스로 코핑을 제작하여 매몰, 주조과정을 통해서 금속구조물을 제작하 였지만, 디지털 변화에 따른 $\mathrm{CAD} / \mathrm{CAM}$ 시스템으로 바뀌 게 되면서 컴퓨터에 의한 지대치 스캔과정, 수복물 설계, 가공과정을 통해 기존의 방식보다 제작 시간과 비용을 절 감 과 대량생산이 가능해졌고, 일반적인 수복물 제작 시 발생할 수 있는 변형 문제를 최소화 할 수 있다(Tinschert, 2001). $\mathrm{CAD} / \mathrm{CAM}$ 기계가 보편화되고, $\mathrm{CAD} / \mathrm{CAM}$ 전용 금속합금이 시중에 많이 유통이 되어 사용되고 있음에도 불구하고 $\mathrm{CAD} / \mathrm{CAM}$ 전용 금속합금과 세라믹의 결합강 도에 대한 연구는 전무한 실정이다. 금속-세라믹 보철의 성공여부는 금속과 세라믹간의 결합강도에 의해 결정되 기 때문에(Craig, 1997; McCabe, 1994), CAD/CAM 전 용 금속합금의 안전성에 대한 연구가 필요한 실정이다.

이에 본 연구에서는 국산 $\mathrm{CAD} / \mathrm{CAM}$ 전용 금속합금, 외 산 $\mathrm{CAD} / \mathrm{CAM}$ 전용 금속합금, 주조용 합금이 도재와의
결합강도(Bond strength) 차이를 측정 및 평가하여, 국산 $\mathrm{CAD} / \mathrm{CAM}$ 전용 금속합금의 타당성을 알아보고자 한다.

\section{II. 연구 방법}

\section{1. 연구 재료}

실험에 사용되는 합금은 $\mathrm{CAD} / \mathrm{CAM}$ 전용 금속합금 3 종 과 주조용 합금 1 종으로 세라믹과의 결합강도를 관찰하기 위하여 임상에서 사용되는 Myeong Moon Dental 함량 이 다른 2종, Mesa, Casting Type 4종을 선택하였다. 도재분말은 Noritake EX-3을 사용하였고, 각 회사의 제 품을 5 개씩 측정하여 총 20 개의 시편을 대상으로 측정하 였고, 각 각의 금속-세라믹 합금을 순서대로 Group 1 4 로 분류하였다(Table 1).

Table 1. Materials of specimen metal

\begin{tabular}{ccc}
\hline Block & Manufacturer & N \\
\hline Group 1 & MyeongMoon Dental, Korea Cr 30\% & 5 \\
Group 2 & MyeongMoon Dental, Korea Cr $40 \%$ & 5 \\
Group 3 & Mesa, Italy & 5 \\
Group 4 & casting type, China & 5 \\
\hline
\end{tabular}

\section{2. 금속시편 제작}

$\mathrm{CAD} / \mathrm{CAM}$ 용 전용 금속합금 금속시편은 Milling Machine(DM-25, Daesung Ltd., Korea)을 사용하여 ISO9693 규격에 맞게 $25 \mathrm{~mm} \pm 1 \mathrm{~mm} \times 3 \mathrm{~mm} \pm 0.1 \mathrm{~mm} \times 0.5 \mathrm{~mm} \pm$ $0.05 \mathrm{~mm}$ 의 직사각형 형태로 제작하였고(Fig 1), 주조용 금 속시편은 wax를 이용하여 $27 \mathrm{~mm} \times 3 \mathrm{~mm} \times 0.6 \mathrm{~mm}$ 의 크기로 제작하였고, 인산염계 매몰재로 매몰하고 니켈-크롬합금 을 사용하여 제조사 의 지시에 따라 소환, 주조하여 제작 하였다. 주입선을 절단한 주조시편을 ISO9693 규격에 맞 게 $25 \mathrm{~mm} \times 3 \mathrm{~mm} \times 0.5 \mathrm{~mm}$ 크기가 되도록 기공용 carbide bur 와 $\mathrm{SiC}$ paper로 조정하고 도재피개면을 연마하였으며, $250 \mu \mathrm{m}$ alumina oxide를 $3 \mathrm{bar}$ 의 압력으로 분사한 후 초음파세척과 증기세척을 하였다(Fig 2). 


\section{3. 도재의 소성}

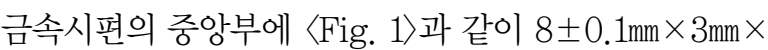
$1.1 \pm 0.1 \mathrm{~mm}$ 크기의 도재층을 형성하기 위하여, 제조사의 지시에 따라 Group 4 시편 군은 degassing 과정을 시행 하고, 나머지 군의 시편은 degassing 과정은 시행하지 않 았다. 그 다음 불투명 도재소성 1 회, 상아질색 도재소성 1 회 그리고 glazing 소성을 하였다. 상아질색 도재의 축성
에는 분할형 금속틀을 사용하여 도재가 균일한 두께를 이 루고, 도재-금속 변연부의 명확한 경계를 이루도록 하였 으며, 세라믹 층은 직사각형 형태로 필요한 두께 및 모양 을 얻기 위해 바디 세라믹을 추가하여 소성하고, 디스크 를 이용해 직사각형 형태를 주의하여 마감 처리하였다 (Fig 3, 4, 5, 6).
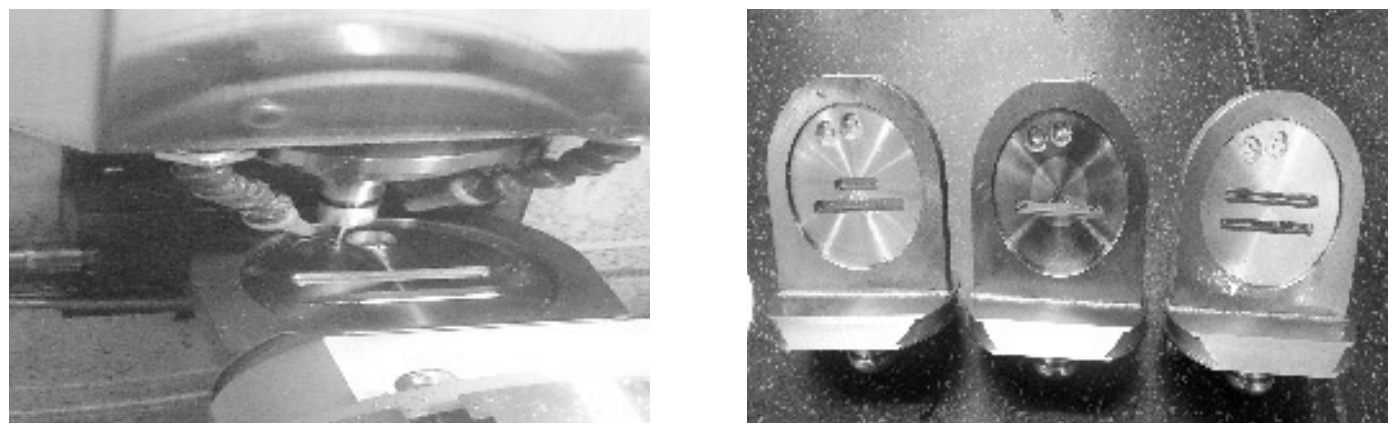

Fig. 1. DM-25 Milling

\section{3점 굴곡강도 측정}

합금과 도재와의 결합강도를 측정하기 위해 만능시험기 (Model 3366, Instron Inc., USA)로 지지대 사이의 거리 가 $20 \mathrm{~mm}$ 인 3 점 굽힘 시험장치로 크로스헤드 속도는 $1.5 \pm$ $0.5 \mathrm{~mm} / \mathrm{min}$ 의 일정한 속도로 적용하였으며, 지지대와 굽 힘 봉의 끝은 반경이 $1 \mathrm{~mm}$ 인 반구형으로 시편 각각에 대해 측정한 파단력(fracture force) Ffail(뉴턴)은 세라믹 층 의 한쪽 끝에서 분리 균열 발생에 의해 파절된 시료 (Specimens failing)로 측정하였고, 다음 공식에 따라 결 합강도를 계산하였다(Fig 7).

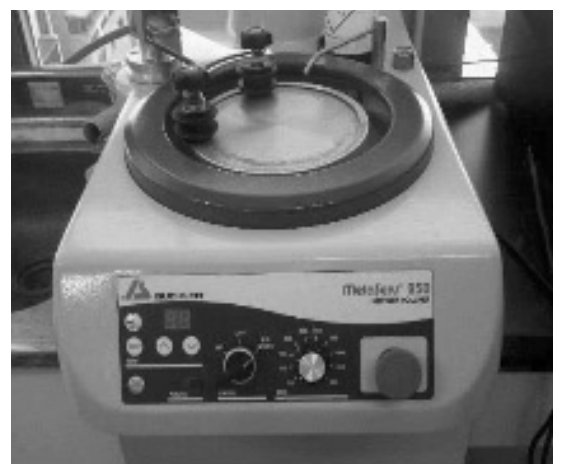

Fig. 2. Metaserv 250

$\tau b=k \cdot F_{\text {fail }}$

여기서 $F_{\text {fail }}$ 는 측정된 파단력이며, $\mathrm{k}$ 는 시편의 탄성계수 와 두께에 따라 결정되는 상수이며, $\tau b$ 는 결합 강도를 나 타낸다.

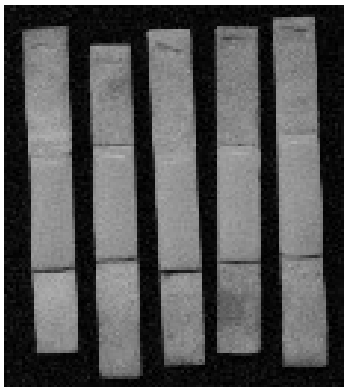

Fig. 3. Group 1

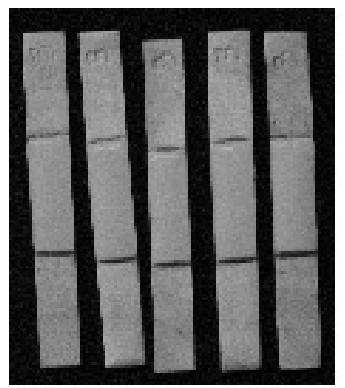

Fig. 5. Group 3

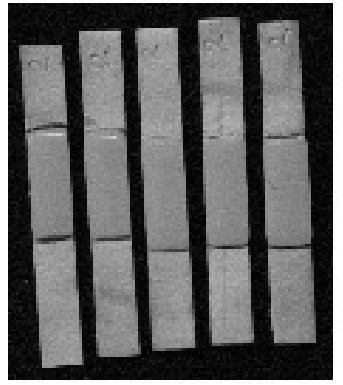

Fig. 4. Group 2

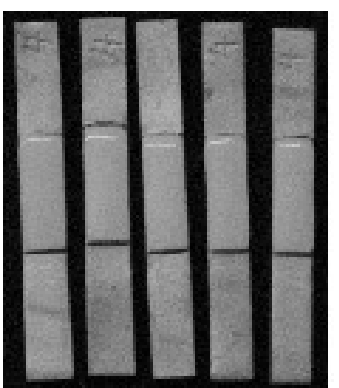

Fig. 6. Group 4 

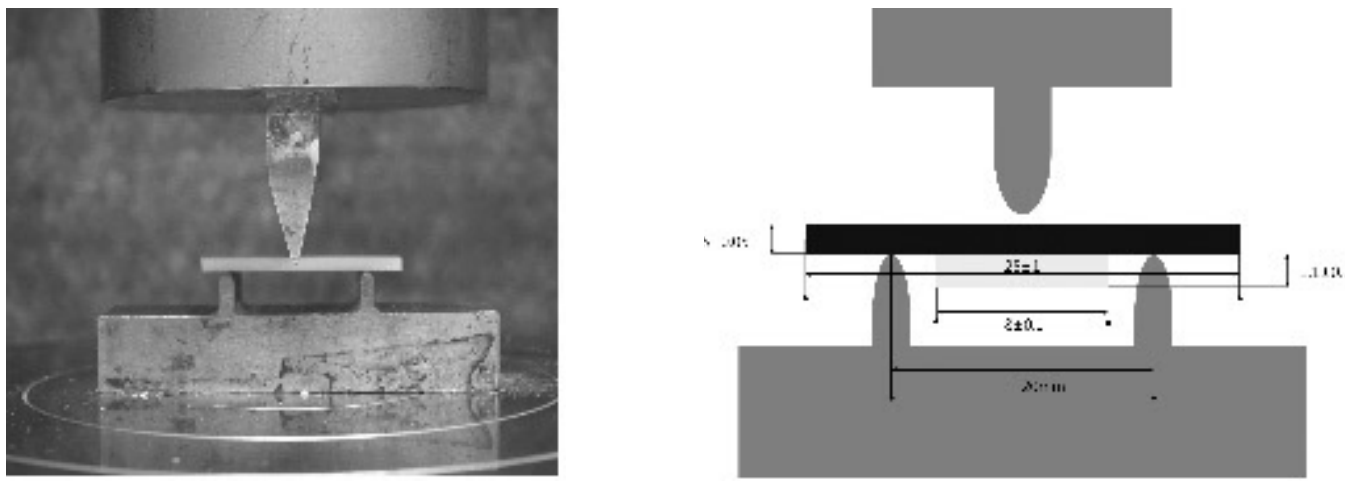

Fig. 7. Scheme of the 3-point flexure test

\section{5. 통계 처리}

통계 처리는 SPSS(Statistical Package for Social Sciences) 19.0 for windows을 이용하여 분석하였다. 각 블록의 결합강도에 따른 값의 유의차를 검정하기 위해 Kruskal-Wallis test을 시행하였고, 모든 통계는 $95 \%$ 의 유의수준에서 검정되었다.

\section{III. 결 과}

금속시편의 3 점 굴곡시험을 시행하여 결합강도를 측정
한 결과는 다음과 같다(Table 2). 결합강도 측정결과 Group 1은 36.78 $\pm 9.90 \mathrm{MPa}$, Group 2는 $37.68 \pm 4.51 \mathrm{MPa}$,

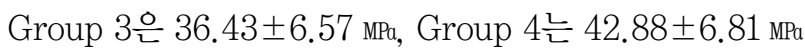
으로 나타났다. Group 4의 주조방식의 도재결합강도가 가장 높은 결합강도를 보였으며, Group 3이 가장적은 결 합강도를 보였다. 각 군 간의 비교를 위해 KruskalWallis test를 시행한 결과로 각 군간의 유의한 차이를 보 이지 않았다(Table 3). 모든 금속시편에서 ISO 9693에 제시하는 메탈과 세라믹의 분리/균열 최소강도 $(25 \mathrm{MPa})$ 강 도보다 높게 나타났다.

Table 2. Mean values of 3-point flexure test results

\begin{tabular}{cccccc}
\hline \multirow{2}{*}{ Cord } & $\begin{array}{c}\text { Modulus of } \\
\text { elasticity(GPa) }\end{array}$ & Mean(Mpa) & $\begin{array}{c}\text { Standard } \\
\text { Deviation }\end{array}$ & Minimum & Maximum \\
\cline { 3 - 6 } & 281 & 36.78 & 9.90 & 25.28 & 52.56 \\
\hline Group 1 & 281 & 37.68 & 4.51 & 31.99 & 42.21 \\
\hline Group 2 & 194 & 36.43 & 6.57 & 25.98 & 41.89 \\
Group 3 & 128.5 & 42.88 & 6.81 & 35.56 & 51.03 \\
\hline Group 4 & & & & & \\
\hline
\end{tabular}

Table 3. Kruskal-Wallis test(bond strength)

\begin{tabular}{cccccc}
\hline Characteristic & N & Mean Rank & df & $x^{2}$ & p \\
\hline Group 1 & 5 & 8.40 & & & \\
Group 2 & 5 & 10.20 & & & .417 \\
Group 3 & 5 & 9.20 & 3 & 2.840 & \\
Group 4 & 5 & 14.20 & & & \\
\hline
\end{tabular}




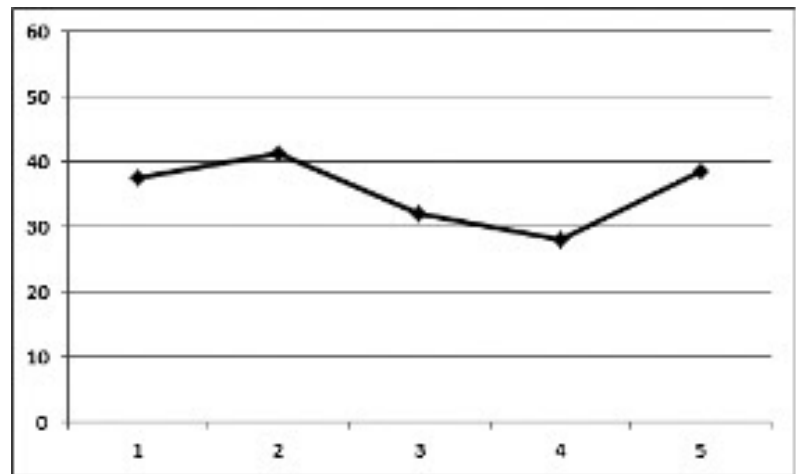

Fig. 8. Group 1

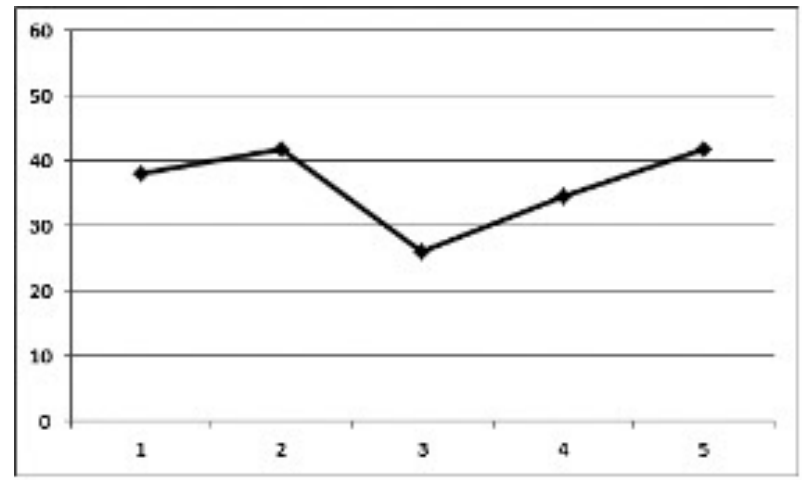

Fig. 10. Group 3

\section{IV. 고 찰}

금속과 도재 간의 결합은 계면을 통해 확산되는 금속 산 화물로부터 얻는 화학적 결합력, 금속 표면의 불규칙한 면으로 소성된 도재의 locking에 의한 물리적 결합력, 도 재와 금속의 열팽창 차이로 인한 압축력 등에 의해 영향 을 받는다(Root and Findley, 1976). 금속과 도재 계면 간의 결합력은 bonding agent의 첨가 등과 같은 도재의 소성 조건 외에도(Yamada et al, 2005), 금속의 표면 특 성에 의해 영향을 받기도 하고(Yilmaz and Dincer, 1999), 샌드블라스팅, 산처리 및 nitride 코팅 등의 처리 방법에 따라 달라진다(Reyes et al, 2001). 샌드블라스팅 은 미세유지형태와 증가된 표면적을 제공하기 위하여 사 용되며, 그 결과 표면은 매우 활성화되며 젖음성이 증가 하게 된다(Tiller et al, 1985). 비귀금속 합금과 세라믹간 의 파절양상이 접착파절보다 결합강도가 강한 복합파절 양상을 보이는 것은 금속과 세라믹간의 결합강도를 결정

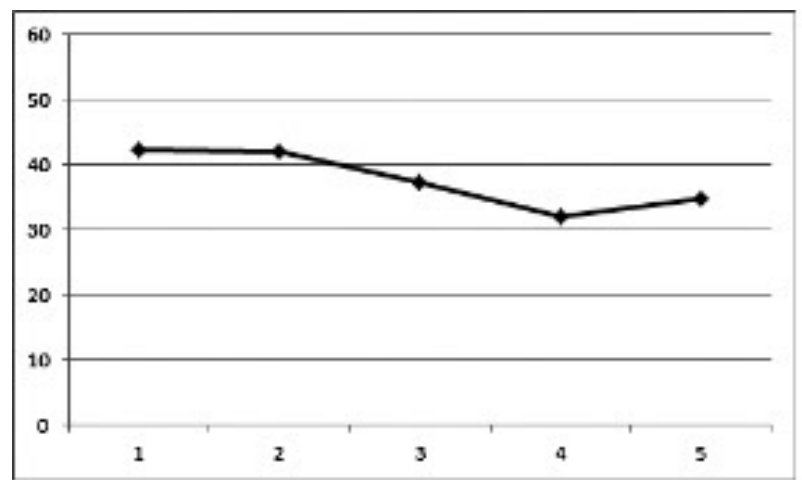

Fig. 9. Group 2

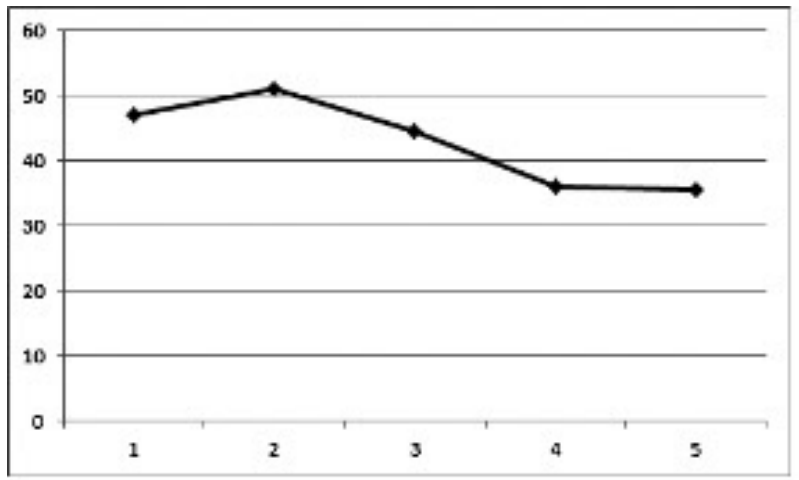

Fig. 11. Group 4

하는 기계적 결합, 분자간 인력, 산화물에 위한 화학적 결 합, 열팽창계수의 불일치에 의해 발생되는 압축력에 의한 결합 그리고 합금의 조성 등에 달라진다(정인성과 김치 영, 2010).

도재용 비귀금속 합금은 기존에 주조방식에서 자동화 방식으로 바뀜에 따라 $\mathrm{CAD} / \mathrm{CAM}$ 전용 금속합금의 사용 이 증가하고 있지만, 주조합금과 $\mathrm{CAD} / \mathrm{CAM}$ 전용 합금에 대한 연구는 전무한 실정이다. 이에 본 연구에서는 $\mathrm{CAD} / \mathrm{CAM}$ 전용 금속합금과 주조용 합금의 세라믹 결합 강도 차이를 파악하기 위해, 소성된 시편은 하중의 반대 편에 대칭적으로 위치한 세라믹 굴곡강도 장치에 놓고, $1.5 \pm 0.5 \mathrm{~mm} / \mathrm{min}$ 의 일정한 속도로 적용하여 파단 될 때까 지 기록하여 5 개의 시편 각각에 대해 측정한 파단력 뉴턴 은 세라믹 층의 한쪽 끝에서 분리 균열 발생에 의해 파절 된 시료로 측정하는 실험방법을 적용하여 임상에서 사용 되고 있는 국산 및 외산 $\mathrm{CAD} / \mathrm{CAM}$ 용 전용 금속합금과 주조용 합금이 세라믹과의 결합강도가 치과수복용으로 
충분한 결합강도를 갖고 있는지를 측정하기 위해 시행하 였다.

본 실험에서 결합강도의 결과는 Group 1은 $36.78 \pm$ $9.90 \mathrm{MPa}$, Group 2는 37.68 $\pm 4.51 \mathrm{MPa}$, Group 3은 36.43 $\pm 6.57 \mathrm{MPa}$, Group 4는 42.88 $\pm 6.81 \mathrm{MPa}$ 으로 주조방식에 비해 $\mathrm{CAD} / \mathrm{CAM}$ 전용 금속합금의 결합강도는 낮게 나타 났다. 이광훈 외(2011)의 귀금속 합량에 따른 금속-도재 합금의 도재와의 결합강도 연구에서는 니켈-크롬 합금은 $40.62 \pm 3.32 \mathrm{MP}$ 을 보였고, $75 \%$ 금합금은 $37.47 \pm 1.57 \mathrm{MPa}$ 을 보였고, $52.5 \%$ 금합금은 $35.85 \pm 1.48 \mathrm{MPo}$ 을 보였고, $51.5 \%$ 금합금은 $35.04 \pm 1.34 \mathrm{MP}$ 을 보였고, $32 \%$ 금합금 은 $33.17 \pm 1.62 \mathrm{MP}$ 을 보였고, $10 \%$ 금합금은 $30.75 \pm 1.21 \mathrm{MPa}$ 로 나타났다. 유지희(2011)의 도재용착주조관용 $\mathrm{Ni}-\mathrm{Cr}$ 합금의 결합강도 차이의 연구에서는 Alphaloy 금속의 결 합강도는 $32.76 \mathrm{MPa}$ 을 보였고, Vera Bond $2 \mathrm{~V}$ 금소의 결 합강도는 $44.22 \mathrm{MP}$ 을 보였고, T4 금속의 결합강도는 $57.21 \mathrm{MPa}$ 로 $\mathrm{CAD} / \mathrm{CAM}$ 전용 금속합금과 비슷한 결합강도 를 보였다. 주조 합금과의 결합강도는 차이가 있었지만 $\mathrm{CAD} / \mathrm{CAM}$ 전용 국산 금속 합금과 외산 금속 합금간의 차이는 경미했고, 메탈과 세라믹의 분리 및 균열 발생 강 도는 적어도 $25 \mathrm{MPa}$ 이상이여야 하는 요구조건을 충족하기 때문에 치과수복용으로 사용하는데 문제가 없을 것으로 사료된다.

\section{V. 결 론}

본 연구에서는 현재 국내?외 임상에서 사용하는 $\mathrm{CAD} / \mathrm{CAM}$ 전용 금속합금과 주조용 합금의 결합강도를 비교하여, 현재 사용되는 주조방식에 비해 $\mathrm{CAD} / \mathrm{CAM}$ 전 용 금속합금의 충분한 결합강도를 보이는지 평가 및 안정 성을 알아보기 위하여 3점 굴곡강도 시험으로 결합강도 를 측정하여 다음과 같은 결론을 얻었다.

1. 결합강도 측정결과 Group 1은 $36.78 \pm 9.90 \mathrm{MPa}$,

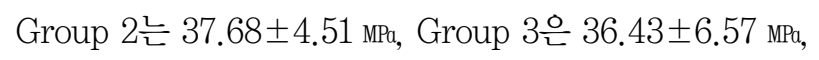
Group 4는 42.88土6.81 Mp으로 나타났다.
2. 결합강도의 비교를 위해 Kruskal-Wallis test를 시 행한 결과 각 군간의 유의한 차이를 보이지 않았다.

3. 주조방식 합금에 비해 $\mathrm{CAD} / \mathrm{CAM}$ 전용 금속합금의 결합강도는 낮게 나타났지만, 메탈과 세라믹의 분리/균열 발생 강도는 $25 \mathrm{MPa}$ 보다는 더 크게 나타났다.

\section{REFERENCES}

Lee KH, Cho YB, Chung CH, Kim HJ, Bondstrength of several metal-meramic alloys and meneered-porcelain. The Journal of Advanced Prosthodontics, 49(3), 191-196, 2011.

Yoo JH. The effect of recasting on bond strength of $\mathrm{Ni}-\mathrm{Cr}$ Free Allorys for Porcelain Fused to Metal. Dankook University master thesis, 2011.

Azer SS, Ayash GM, Johnston WM, Khalil MF, Rosenstiel SF. Effect of esthetic core shades on the final color of IPS Empress all-ceramic crowns, J Prosthet Dentm, 96(1), 397-401, 2006.

Bagby M, Marshall GW. Metal-ceramic compatibility: a review of the literature. J Prosthet Dent, 6(1), 21-26, 1990.

Chung IS, Kim CY. Shear Bond Strength and Interfacial Characterization of Ceramic to Beryllium Free Nonprecious Alloys for Porcelain Fused to Metal Crown. The Journal of Contents, 10(11), 228-234, 2010.

Craig RG. Restorative dental materials. 10th ed, Mosby-year Book Inc, 409-493, 1997.

Dent RJ, Preston JD, Moffa JP, Caputo A. Effect of oxidation on ceramometal bond strength. J Prosthet Dent, 47(1), 59-62, 1982.

Kelly JR, Rose TC. Nonprecious alloys for use in 
fixed prosthodontics: a literature review. J Prosthet Dent, 49(1), 363-370, 1983.

McCabe JF. Applied dental materials. 7th ed, Mass Publishing Co, 71-78, 1994.

Moffa JP, Lugassy AA, Guckes AD, Gettleman L. An evaluation of nonprecious alloys for use with porcelain veneers. J Prosthet Dent, 30(1), 424-431, 1973.

Moffa JP. Alternative dental casting alloys. Dent Clin North Am, 27(1), 733-746, 1983.

Reyes MJ, Oshida Y, Andres CJ, Barco T, Hovijitra S, Brown D. Titanium-porcelain system. Part III: Effects of surface modification on bond strengths. Biomed Mat and Eng, 11(1), 117136, 2001.

Root NS, Findley MM. The bond between porcelain and gold alloys: characteristics and practical considerations. Quintessence Dent Technol, 1 (1), 93-98, 1976.

Tiller HJ, Magnus B, Gobel R, Musil R, Garschke A. Der Sandstrahlproze $\beta$ und seine Einwirkung auf den Oberflächenzustand von Dentallegierungen (I). Quintessenza, 36(1), 1927-1934, 1985.

Tinschert J, Natt G, Mautsch W, Spikermann H, Anusavice KJ. Marginal fit of alumina- and zirconia-based fixed partial dentures produced by a CAD/CAM system. Oper Dent, 26(1), 367-374, 2001.

Yamada K, Onizuka T, Endo K, Ohno H, Swain MV. The influence of GoldbonderTM and pre-heat treatment on the adhesion of titanium alloy and porcelain. J Oral Rehabil, 32(1), 213-220, 2005.

Yilmaz H, Dincer D. Comparison of the bond compatibility of titanium and an $\mathrm{NiCr}$ alloy to dental porcelain. J Dentistry, 27(1), 215-222, 2005. 